\title{
Potencial Produtor de Biogás a partir dos Dejetos de Galinhas Poedeiras em São Bento do Una/PE
}

\author{
Potential Producer of Biogas from waste products of laying hens in São Bento do Una/PE
}

Ingred Rhayane Rago Gomes 1,2 (D) https://orcid.org/0000-0002-4451-1334

Sergio Peres Ramos da Silva 1,2 (D) https://orcid.org/0000-0002-2235-3507

${ }^{1}$ Escola Politécnica de Pernambuco, Universidade de Pernambuco, Recife, Brasil,

2 Pós-graduação em Energias Renováveis, Escola Politécnica de Pernambuco, Pernambuco, Brasil,

E-mail do autor principal: Ingred Rago ingred.rago@gmail.com

\section{Resumo}

É crescente a preocupação acerca das questões ambientais que definem a qualidade de vida numa sociedade. Conceitos como "sustentabilidade" e "eficiência energética" estão sendo incorporados na logística dos processos produtivos, face a movimentação da cadeia reversa de suprimentos responsável pelo retorno dos rejeitos à produção. Esse movimento incide sobre a diminuição do consumo energético e consequente redução de energia e de gastos com exploração de novos insumos. Face a isso, objetivo do trabalho consiste em estudar o potencial de produção do biogás a partir de resíduos orgânicos provenientes da criação de galinhas poedeiras na cidade de São Bento do Una/PE, cuja comporta um efetivo de 2.864.946 galinhas. Devido à escala de criação a cidade é referência no estado, elevando a capacidade produtiva. Nesse contexto, a implantação de sistemas de biodigestão dos resíduos, além de impulsionar a economia local, soluciona-lhes a destinação. Através do estudo do potencial de produção de biogás a partir da criação de galinhas poedeiras percebe-se a valoração dos rejeitos e o potencial de investimentos em agronegócio e bioenergia. Diante disso, faz-se necessário a elaboração de políticas públicas que explorem o potencial produtor de biogás dessa região e auxiliem na gestão desses resíduos.

Palavras-Chave: Energia; Logística; Eficiência energética; Biodigestão.

\begin{abstract}
Is growing concern about the environmental issues that define the quality of life in a society. Concepts such as "sustainability" and "energy efficiency" are being incorporated into the logistics of the production processes, in the face of reverse supply chain movement responsible for the return of waste production. This movement focuses on reducing energy consumption and consequent reduction of energy and operating costs of new inputs. In the face of this, objective of this work is to study the potential of biogas production from organic wastes arising from the creation of laying hens in São Bento do Una/PE, which involves an effective 2,864,946 chickens. Due to the scale of creation the city is a reference in the State, raising the productive capacity. In this context, the implementation of systems of waste biodigestion, in addition to boost the local economy, solves their destination. Through the study of biogas production potential from the creation of laying hens realizes the valuation of tailings and potential for investments in agribusiness and bioenergy. Given this, it is necessary to draw up public policies that exploit the potential of biogas producer in this region and assist in the management of such waste.
\end{abstract}

Key-words: Energy; Logistics; Energy efficiency; Biogigestão. 


\section{Introdução}

A crescente utilização de fontes renováveis na matriz energética brasileira é uma realidade que endossa o anseio por uma nação autossustentável e soberana energeticamente. A fim de tornar a sociedade menos suscetível aos impactos adversos diante da crise de recursos ambientais que se instaura, o uso integrado das fontes, ou seja, a incorporação de recursos renováveis no processo de geração de energia, representa uma estratégia eficiente no tocante à minimização de tais impactos.

Além disso, o incentivo ao uso de fontes alternativas na matriz do país opera também no âmbito do desenvolvimento sustentável, considerando que a utilização de resíduos de atividades agrícola e agropecuária como insumo no processamento de matéria-prima energética, como o biogás, acarreta além impulsão da economia local, impactos positivos no meio ambiente.

Nesse contexto, o biogás produzido a partir da utilização da biomassa residual, além de atuar na composição da geração mais limpa, serve como alternativa ao setor de transportes, tendo em vista a participação na produção de biocombustíveis, a qual reflete indiretamente na diminuição de Gases de Efeito Estufa (GEE), concorrendo para a preservação da qualidade ambiental.

O biogás pode ser definido como derivado do processo de biodigestão, composto gasoso constituído de gás metano $(\mathrm{CH} 4)$, principal componente presente, de gás carbônico ( $\mathrm{CO} 2)$ e de gases-traço, entre eles o gás sulfídrico (H2S). Além desse derivado, a degradação biológica dos resíduos resulta nos insumos necessários à composição de biofertilizantes

[1].

Precedentemente visto como subproduto resultante da biodegradação anaeróbica de resíduos orgânicos, o biogás transitou da invisibilidade desse título para o conceito de produto energético, visto que representa a matéria prima necessária para produção de Biometano, um combustível passível de ser inserido no cenário da atual matriz energética nacional.

Com base nisso, o trabalho em questão representa um estudo teórico respaldado em pesquisas bibliográficas, análise e interpretação de dados.

\section{Objetivo Geral}

Estudar o potencial de produção de biogás gerado a partir da biomassa residual proveniente da criação regional de galinhas poedeiras em São Bento do Una, situada no Agreste pernambucano. Além de reconhecer a importância desses resíduos para o desenvolvimento local, face ao estímulo à agroenergia, agronegócio, incentivo à geração distribuída com fontes renováveis de energia, e relevância em se ter uma matriz energética autossustentável.

\subsection{Objetivos Específicos}

- Estimar a produção regional de biomassa residual resultante do efetivo total de galinhas poedeiras da cidade de são Bento do Una/PE e interpretar os resultados atingidos, tendo em vista a verificação de potencial indicador de geração de biogás;

- Calcular o potencial de produção de biogás na localidade supracitada, baseado na produção regional de biomassa, tendo em vista a verificação deste potencial face a viabilidade sócioeconômica-ambiental em se adotar medidas propulsoras de eficiência energética.

- Fomentar o incentivo à elaboração de políticas públicas que visem integrar os pontos de produção de biomassa distribuídos na cidade, para que forneçam subsídio necessário para o tratamento desses resíduos biodigestores - tendo em vista a constituição de uma rede integrada de produção de biogás a partir da biomassa residual proveniente da criação de galinhas poedeiras. 


\section{Metodologia}

O delineamento do estudo constituiu de levantamento bibliográfico e estudo de caso, no qual a coleta de dados primários e secundários comportaram os instrumentos de pesquisa empregados [2].

O ambiente de desenvolvimento teórico foi a cidade de São Bento do Una, situada na Mesorregião do Agreste pernambucano. A cidade possui o efetivo total com cerca de 8.864.946 cabeças de aves, das quais 2.864.946 correspondem à galinhas poedeiras.

Essa grande escala de criação de galinhas, resulta em 54.420 .000 dúzias de ovos produzidos, cujo valor de produção é $R \$ 163.259 .000,00$ (cento e sessenta e três milhões duzentos e cinquenta e nove mil reais)

[3].

Com base nos dados coletados, estimou-se as produção regional de biomassa, que serviu como subsídio para o cálculo do quantitativo de produção local de biogás, necessário à verificação do potencial produtor de São Bento do Una. Seguidamente, os resultados obtidos foram analisados e interpretados tendo em vista a redação deste produto.

A metodologia foi constituída basicamente de cinco etapas, esquematicamente apresentadas conforma a Figura 1:

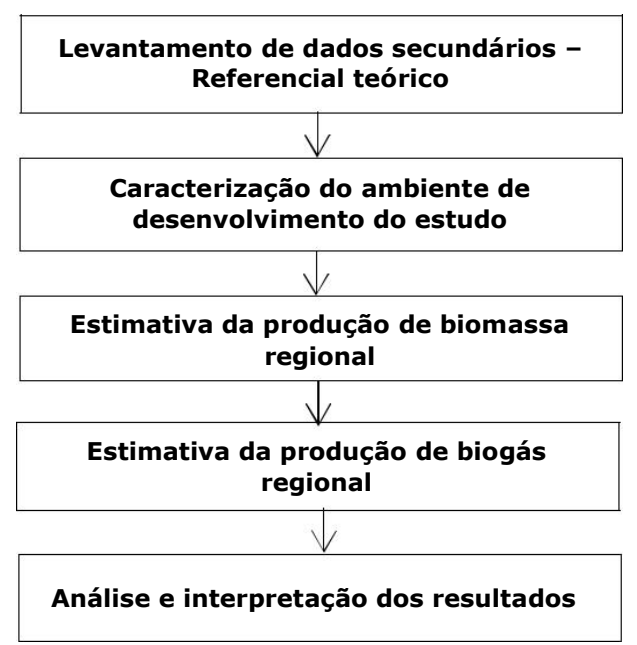

Figura 1: Esquema de etapas desenvolvidas no estudo. Fonte: Autor (2017).

\section{Soberania Energética}

O uso de fontes limpas de energia na composição da matriz de oferta energética no país cresce em proporções substantivas diante da necessidade de possuir alternativas de conclusão do sistema operante. Tendo em vista a dependência que envolve o petróleo e os seus derivados, o incentivo à utilização de recursos renováveis para obtenção de energia atua como mecanismo de fomento à soberania energética.

\subsection{Biogás na Matriz Energética do Brasil}

De acordo com o Balanço Energético Nacional [4] elaborado pela Empresa de Pesquisa Energética (EPE), no ano de 2015 o percentual de participação de fontes renováveis na matriz energética do país foi de $41,2 \%$, representando um crescimento de $7,2 \%$ em relação ao ano de 2014 (39,4\%). Ainda que sucinto, tal crescimento esteve associado à redução da atividade econômica que resultou na diminuição da quantidade disponível de petróleo e derivados.

Com base na repartição da oferta interna de energia, verificou-se que do percentual de renováveis presente na matriz, cerca de $4,7 \%$ englobam a lixívia e outras fontes, dentre as quais está inserida o biogás representando $0,7 \%$. Conforme aponta o balanço, o biogás apresentou variação positiva equivalente a $44 \%$ entre os anos de 2014 e 2015 conforme mostra a Tabela 1. Subindo de 73 para 104 mil tep nos respectivos anos [4].

Tabela 1: Repartição da oferta interna de energia.

\begin{tabular}{|llll|}
\hline $\begin{array}{l}\text { Lixívia e outras } \\
\text { renováveis (mil tep) }\end{array}$ & $\mathbf{2 0 1 5}$ & $\mathbf{2 0 1 4}$ & \multicolumn{1}{c|}{$\mathbf{1 5}$ / } \\
\hline Lixívia & 7.905 & 7.393 & $7 \%$ \\
Biodiesel & 3.126 & 2.686 & $16 \%$ \\
Outras biomassas & 1.152 & 1.122 & $3 \%$ \\
\hline Biogás & 104 & 73 & $44 \%$ \\
\hline Gás industrial de carvão & 43 & 35 & $21 \%$ \\
vegetal & 1.860 & 1.045 & $78 \%$ \\
Eólica & 1,4 & 0,7 & $97 \%$ \\
Solar & $\mathbf{1 4 . 1 9 1}$ & $\mathbf{1 2 . 3 5 3}$ & $15 \%$ \\
Total & 120 : Tonelada equivalente à petróleo. \\
1 tep : & \\
Fonte: Adaptado de Balanço Energético Nacional (2016).
\end{tabular}


Estes dados são resultantes de fatores como decaimento do consumo de petróleo e, principalmente no tocante ao biogás, do grande volume de biomassa residual gerado pela agropecuária e agroindustrialização que, devido aos estímulos do agronegócio estão sendo utilizados como insumo nos processos de geração sustentável de energia.

\section{Agroenergia}

O inegável aumento da gama dos empreendimentos ligados à agropecuária, atrelado às novas proporções, dentro das quais tais projetos passam a serem executados, resultam numa busca incessante pela mitigação dos impactos negativos ao meio ambiente e minimização dos custos demandados pela produção.

No setor do agronegócio, tem-se observado uma relação de proporcionalidade inversa entre a escala de produção e a sustentabilidade, inferindo que quanto maior for a escala produtiva, mais insustentável ambientalmente se torna o processo. Na prática, essa relação diverge da concepção convencional de mercado, que não aceita perder lucros e nem ganhar prejuízos.

Assim sendo, quanto maior for a escala do processo, maior será a geração de carga poluidora e, consequentemente, maior será a demanda por tratamento ambientalmente adequado e compatível com a proporção da produção [5].

Como forma de otimizar tais processos, os tornando cada vez mais eficientes, a energia tipicamente utilizada como input da produção rural, retorna através da matéria prima necessária ao funcionamento complementar do processo de origem ou outro em que seja necessário.

Nesse contexto, a agroenergia é um mecanismo que explora o potencial do ambiente agrícola, haja vista os múltiplos usos que seus recursos podem oferecer. Isto é, da produção agropecuária pode-se conseguir, além da função típica de abastecimento humano, fornecer co-produtos e subprodutos e ainda participar da geração de energia.

Em linhas gerais, agroenergia é a atividade que utiliza os recursos do ambiente agrícola na geração de energia, propiciando o surgimento de um ambiente agroenergético.
Diante disso, o ambiente agroenergético é percebido quando da constatação da remodelagem do cenário rural, que, conforme a necessidade em obterse eficiência energética e desenvolvimento sustentável, ultrapassou a interface rural convencional, transgredindo para um novo cenário cujo escopo se tornou a produção de energia.

É sabido que no ano de 2015 o percentual de participação de fontes renováveis na matriz do país foi de 41,2\% [4], demonstrando uma inclinação à produção energética mais limpa. À luz disso, a matriz, na qual participam as fontes renováveis, como recursos complementares, anuncia a formatação do modelo de produção agrícola identificada como Matriz Energética Renovável Rural (MERR).

O entendimento da MERR e, consequentemente, do significado da agroenergia no tocante à sustentabilidade e independência energética, é desencadeado através de premissas que fundamentam a importância da integração das fontes renováveis e otimização dos recursos. Dessa maneira, a formulação de Políticas Públicas, Gestão territorial, o uso Integrado das Fontes, Eficiência Energética e a Geração Distribuída, são aspectos imprescindíveis que devem ser levados em consideração quanto a logística das atividades agrícola e agropecuária quando no exercício da função de produção de recursos energéticos. Tais aspectos, permitem, por assim dizer, que gestores locais possam atuar como colaboradores na geração de energia [1].

Depreende-se que o processamento dos insumos energéticos através do beneficiamento dos resíduos do próprio sistema de produção, resulta do exercício da gestão ambiental vinculada ao desenvolvimento sustentável.

Nesse cenário, o biogás surge como resultado das potencialidades oferecidas pelo meio rural, sendo considerado produto energético resultante do beneficiamento dos resíduos da produção agrícola/agropecuária. Dessa maneira, estando passível de amparos legais, políticas e regulamentos, que forneçam a segurança energética necessária, a exemplo da Instrução Normativa no 390/2009, publicada em 2009 pela Agência Nacional de Energia Elétrica (ANEEL), que dispõe da regulamentação da geração distribuída de energia com biogás e saneamento ambiental. 


\section{Aproveitamento do Resíduo Sólido Pecuário (RSP) na produção de biogás}

Atualmente, é crescente a aflição da sociedade no tocante aos impactos ambientais negativos causados pelo manejo invasivo dos recursos naturais até então disponíveis. Como forma de mitigar tais impactos, manter a qualidade ambiental e, em paralelo, minimizar os custos com a exploração de recursos e a geração de energia, os grandes volumes de biomassa residual resultantes da produção agropecuária estão sendo utilizados como insumo nos processos de geração sustentável.

Essa preocupação socioambiental é reflexo involuntário dos impactos ambientais negativos (que incidem especialmente sobre os recursos hídricos e a conservação dos solos), os quais, resultam do grande volume de gases gerados (carbônico, sulfídrico, metano) quando esses resíduos se encontram disponíveis no ambiente em condição natural, ou seja, em estado bruto.

Com o aumento da demanda por alimentação e energia e, consequentemente, da escala dos processos produtivos, a capacidade típica que o meio ambiente possui de processar as cargas carbonáceas decai em função do tempo, se tornando cada vez mais irremediável a degradação do meio [11].

Atrelado a isso, há ainda insuficiência de equipamentos necessários para o tratamento das grandes quantidades de efluentes e resíduos orgânicos gerados do começo ao fim dos processos

produtivos, proporcionais a escala dos empreendimentos.

Diante disso, a prática da gestão ambiental e das condutas sustentáveis quando aplicadas em qualquer que seja a cadeia de produção, faz com que a atividade se torne limpa, eficiente e predominantemente legal. Além da perspectiva ambiental, o resultado econômico observado quando seguidas essas condutas, como a diminuição dos custos com exploração de recursos, fundamenta o incentivo para o beneficiamento da biomassa dos resíduos na produção de energia elétrica sob a ótica de geração distribuída.
O aproveitamento da biomassa residual reitera o conceito de logística reversa, que prevê o retorno do resíduo à cadeia produtiva, ou caso contrário, forneça uma destinação ambientalmente adequada, ou seja, tratamento em função da necessidade. A implementação e estruturação do sistema de logística reversa é um subterfúgio para assegurar responsabilidade do homem pela manutenção da qualidade do meio.

No que tange os resíduos, inúmeras são as variedades fornecidas pela atividade agrícola, disponíveis para tratamento. Nesse contexto, a biomassa deve conter em sua composição básica moléculas proteicas, carboidratos, gorduras, hemicelulose e celulose [6].

Considera-se biomassa residual os resíduos de vegetais quando esgotadas as possibilidades de aproveitamento para consumo ou plantio, bem como os efluentes sólidos e líquidos resultantes da atividade agropecuária, como os dejetos produzidos no matrizeiro ou galináceo. A produção desses resíduos deve ser incorporada no planejamento produtivo, o que refletirá na qualidade e no volume gerado [5].

\section{Processo de Geração de Biogás}

Em linhas gerais, o biogás é um composto gasoso, constituído em maior parte por metano $(\mathrm{CH} 4)$ e gás carbônico ( $\mathrm{CO} 2)$, e além desses, estão presentes em baixas concentrações gases como o nitrogênio (N2) e o gás sulfídrico (H2S). O potencial energético desse produto, depende tanto da concentração de metano presente na biomassa quanto da solubilidade dos gases constituintes em relação a água. Visto que durante a etapa de purificação do biogás em biometano, são empregadas técnicas de "lavagem", as quais atuam removendo gases $(\mathrm{CO} 2, \mathrm{H} 2 \mathrm{~S})$, tendo em vista o aumento da quantidade de energia por massa, ou seja, o poder calorífico do biogás [7].

O processo de geração do biogás utiliza como procedimento biológico fundamental a degradação anaeróbia dos dejetos orgânicos através de um processo fermentativo e oxidativo, que opera em regime anaeróbio. Dessa decomposição anaeróbia resulta gás carbônico e o metano $(\mathrm{CH} 4)$, este o principal gás constituinte da composição do biogás. 
A compreensão acerca dos procedimentos de geração do biogás é tão importante quanto o êxito tecnológico do seu aproveitamento, a julgar pelo risco de ineficiência do processo caso não seja estabelecido o controle de qualidade necessário ao bom funcionamento [7].

À vista disso, a degradação anaeróbia dos resíduos, realizada por micro-organismos associados (bactérias), processa-se em 4 etapas: Hidrólise, Acidogênese, Aceto-gênese e Metanogênese, respectivamente, como aponta a Figura 2 .

\begin{tabular}{|c|}
\hline Polimeros (carboidratos, polissacarideos, gorduras) \\
\hline Hidrólise \\
\hline Monômeros: glicose, aminoácidos, ácidos graxos \\
\hline Acidogênse \\
\hline Ácidos orgânicos, álcoois e cetonas \\
\hline Acetogênese \\
\hline Acetato, hidrogênio e gás carbônico \\
\hline Metanogênese \\
\hline Metano e hidrogênio \\
\hline
\end{tabular}

Figura 2: Etapas da degradação anaeróbia.

Fonte: Adaptado de Bitton (2017).

Na hidrólise, os polímeros ou moléculas orgânicas complexas, como carboidratos, polissacarídeos e gorduras, são fracionadas em compostos mais simples (monômeros) como glicose, aminoácidos e ácidos graxos, através da ação de enzimas expelidas pelas bactérias fermentativas, como forma de viabilizar a assimilação da matéria orgânica polimerizada.

Os monômeros decorrentes da hidrólise são transformados, atuação das bactérias fermentativas, em ácidos orgânicos, álcoois e cetonas, nessa etapa denominada acidogênese. Nesse momento, o aspecto de maior importância é a concentração de hidrogênio dissolvido, considerando que altas concentrações refletem na diminuição do $\mathrm{pH}$ da mistura, haja vista que os as bactérias produtoras de metano, possuem ótimo crescimento numa faixa de $\mathrm{pH}$ entre 6,6 a 7,4. Entretanto, a estabilidade produtiva no processo pode ser obtida numa faixa de pH entre 6,0 e 8,0 [7].
A acetogênese, é a fase na qual os compostos foma-dos da acidogênese são transformados em acetato, hi-drogênio e gás carbônico por bactérias acetogênicas. Nessa etapa, a preocupação com a concentração de hidrogênio se repete, sendo primordial a manutenção do equilíbrio para que a quantidade de hidrogênio gerado seja consumido pelas arqueas metanogênicas, responsáveis pela metanogênese. Na etapa final, a produção de metano ocorre conforme os substratos provenientes da fase anterior. Nesse contexto, ocorre a geração de metano e gás carbônico derivados do ácido acético, através das Metanogênicas aceto-clásticas, ou por meio de Hidrogênio e o gás carbônico, pela ação das Metanogênicas hidrogenotróficas [7].

Com o objetivo de preservar a eficiência do processo de geração de biogás, diversos fatores demandam controle pontual no decorrer dos procedimentos. São eles: composição química do resíduo, oxigênio, temperatura, $\mathrm{pH}$, alcalinidade, acidez, produção e consumo de ácidos orgânicos, nutrientes, e outros, tanto quanto a presença de químicos como antibióticos, inseticidas, e desinfetantes dentro do biodigestor.

\section{Caracterização do Ambiente de Estudo}

O ambiente de desenvolvimento teórico acontece na Mesorregião do Agreste pernambucano, pontualmente na cidade de São Bento do Una. Que comporta em seu efetivo total cerca de 8.864.946 cabeças de aves, dos quais 2.864 .946 correspondem à galinhas poedeiras. A quantidade de ovos produzidos é de 54.420 .000 dúzias, cujo valor de produção é R\$163.259.000,00 (cento e sessenta e três milhões duzentos e cinquenta e nove mil reais) [3].

Devido à grande escala de criação de galináceos, e produção de ovos, a cidade é uma referência no estado no que diz respeito à implantação de sistemas de tratamento de resíduos anaeróbios, como biodigestores inicialmente com o intuito de obter gás de cozinha.

O incentivo à implantação desses sistemas é fundamental para impulsionar a economia local e solucionar questões como a destinação dos resíduos da agropecuária. Nesse sentido, a destinação 
inadequada de resíduos representa um risco social e ambiental, haja vista que interfere negativamente na saúde pública quando favorece a contaminação pelos vetores atraídos pelos resíduos. Além disso, a não destinação adequada contribui para a contaminação dos lençóis freáticos por meio da percolação de substancias nocivas ao meio.

A figura 3, retrata o ranking de São Bento do Una/PE em relação ao estado e ao país, no que diz respeito ao valor do efetivo total de galinhas. Diante disso, percebe-se que a cidade é um polo produtivo tanto na criação de galinhas quanto no volume dos resíduos gerados.

$$
\begin{aligned}
& \text { Galináceo / Efetivo do rebanho / Galinha (Unidade: cabeças ) } \\
& 200420052006200720082009201020112012201320142015
\end{aligned}
$$

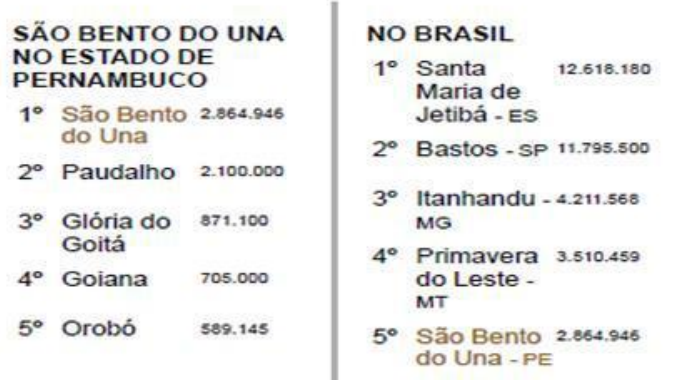

Figura 2: Posição de São Bento do Una em relação a Pernambuco e ao Brasil. Fonte: IBGE (2015).

\section{Resultados e Discussão}

Para estimar a produção de biomassa residual resultante do efetivo total de galinhas poedeiras da cidade de são Bento do Una considerou-se os valores presentes na Tabela 2 [9].

Tabela 2: Potencial de geração de biogás a partir de dejetos de diferentes animais.

\begin{tabular}{cccc}
\multicolumn{4}{c}{ Quantidade em SV } \\
\hline $\begin{array}{c}\text { Anima } \\
\mathbf{I}\end{array}$ \\
$\begin{array}{c}\text { (peso } \\
\text { vivo) } \\
\text { Bovino } \\
(500\end{array}$ & $\begin{array}{c}\mathbf{K g} \\
\text { esterco/animal.di } \\
\mathbf{a}\end{array}$ & $\begin{array}{c}\mathbf{m}^{\mathbf{3}} \\
\text { biogás } / \mathbf{k} \\
\mathbf{g} \text { esterco }\end{array}$ & $\begin{array}{c}\mathbf{m}^{\mathbf{3}} \text { biogás } \\
\text { /animal.di } \\
\mathbf{a}\end{array}$ \\
$\mathrm{kg})$ & $10-15$ & 0,038 & 0,36 \\
$\begin{array}{c}\text { Suíno } \\
(90 \mathrm{~kg})\end{array}$ & $2,3-2,8$ & 0,079 & 0,24 \\
$\begin{array}{c}\text { Ave } \\
(2,5\end{array}$ & $0,12-0,18$ & 0,050 & 0,014 \\
$\mathrm{~kg})$ & & & \\
\hline
\end{tabular}

Fonte: Oliveira (1993).
Com base nos valores de referência na Tabela 2, estimou-se o peso vivo total do rebanho da região, e o valor de produção de esterco (dejetos sólidos) produzidos em kg/dia (Tabela 3 ).

Tabela 3: Estimativa do peso vivo total e da produção de esterco por dia.

\begin{tabular}{cccc}
$\begin{array}{c}\text { Galinha } \\
\text { poedeira }\end{array}$ & Quantidade & $\begin{array}{c}\text { Peso vivo } \\
\text { (kg) }\end{array}$ & $\begin{array}{c}\text { Dejetos sólidos } \\
\text { (kg/dia) }\end{array}$ \\
\hline Ave & 1 & 2,5 & 0,15 \\
Rebanho & $\begin{array}{c}2864946,00 \\
(1)\end{array}$ & $\begin{array}{c}7162365,00 \\
(2)\end{array}$ & $429741,9(2)$ \\
\hline Fonte: ${ }^{(1)}$ IBGE (2017) ${ }^{(2)}$ Autor (2017).
\end{tabular}

Para o cálculo do potencial de produção do biogás, utilizou-se como parâmetro os sólidos voláteis (SVs). Tais sólidos correspondem à fração biodegradável do dejeto com potencial produtor de biogás.

Com os valores referenciados na tabela 2, foi estimado o volume de biogás gerado por $\mathrm{kg}$ de esterco, bem como os volumes diário e anual produzidos, assim indicados na Tabela 4.

Tabela 4: Estimativa do volume de biogas gerado.

\begin{tabular}{ccc}
$\begin{array}{c}\mathbf{m}^{\mathbf{3}} \text { biogás } / \mathbf{k g} \\
\text { esterco }\end{array}$ & $\begin{array}{c}\mathbf{m}^{\mathbf{3}} \\
\text { biogás/animal.dia }\end{array}$ & $\begin{array}{c}\mathbf{m}^{\mathbf{3}} \\
\text { biogás/animal.ano }\end{array}$ \\
\hline 0,050 & 0,014 & 5,11 \\
21487,095 & 40109,244 & 14639874,06 \\
\hline
\end{tabular}

Fonte: Autor (2017).

Os resultados obtidos na Tabela 4, demonstram que a cidade de São Bento do Una possui alto potencial de produção de biogás, ou seja, comporta capacidade notória de geração de biogás, e consequentemente de energia mais limpa.

Contudo, no ano de 2013, o efetivo de galináceos era de 3.500 .000 cabeças de galinhas. E com base nisso, foi previsto para esse efetivo uma produção anual de biogás de $17.885 .000 \mathrm{~m}^{3} /$ ano [8]. Nesse contexto, o valor obtido na Tabela 4 demonstra que houve quebra de expectativa quanto a produtividade anual da região.

Tal quebra, se justifica em razão de diversas circunstâncias que enfraqueceram a produção regional nos últimos anos, como a crise econômica enfrentada pelo país, a dependência hídrica na produção face a convivência com a seca, o aumento 
do preço dos insumos, como também o aumento do índice de desemprego. Esses são alguns fatores que contribuíram para a queda da produtividade em relação ao valor previsto pelo Inventário da Biomassa Produtora de Biogás em Pernambuco.

\section{Considerações Finais}

Em virtude do que foi mencionado, percebe-se que a cidade de São Bento do Una possui grande potencial de produção de biogás, tendo em vista que é responsável pela maior produção de biomassa residual de galinhas do estado de Pernambuco e a $5^{a}$ maior do Brasil. Tal potencial produtor tem sido pouco explorado, fato que posterga o desenvolvimento local, seja ela social, econômico e ambiental.

Depreende-se deste estudo a necessidade de elaboração de políticas públicas que explorem o potencial produtor de biogás dessa região. É imprescindível a adoção de políticas que atuem na integração dos pontos de produção distribuídos na cidade. Como também, é necessário que se forneçam subsídios necessários para a geração de biogás, ou seja, para o tratamento desses resíduos objetivando geração de energia.

Finalizando, é vantajoso para a região e para o meio ambiente, a constituição de uma rede integrada de produção de biogás, a partir da biomassa residual proveniente da criação de galinhas poedeiras, que contribua para geração de energia renovável, para o desenvolvimento local e preservação da qualidade ambiental.

\section{Referências}

[1] BLEY, Cícero. Biogás: a energia invisível. CIBiogás-ER, 2015.

[2] GIL, Antonio Carlos. Como elaborar projetos de pesquisa. São Paulo, v. 5, n. 61, p. 16-17, 2017.

[3] INSTITUTO BRASILEIRO DE GEOGRAFIA E ESTATÍSTICA. IBGE. Cidades. Disponível em:<http://cidades.ibge.gov.br/xtras/perfil.php?! ang $=\&$ cod mun $=261300 \&$ search $=$ pernambuco $\mid$ sao-bentodo-una>. Acesso em: Ago. 2017.
[4] EMPRESA DE PESQUISA ENERGÉTICA. EPE. Balanço Ener-gético Nacional 2016 - Ano base 2015. EPE, Jun 2016.

[5] BLEY JUNIOR, Cícero et al. Agroenergia da Biomassa Residual: perspectivas energéticas, socioeconômicas e ambientais. Foz do Iguaçu: Itaipu Binacional, 2009.

[6] DEUBLEIN, Dieter; STEINHAUSER, Angelika. Biogas from waste and renewable resources: an introduction. John Wiley \& Sons, 2011.

[7] KUNZ, Airton; HIGARASHI, Martha Mayumi; DE OLIVEIRA, Paulo Armando. Tecnologias para tratamento de resíduos de animais. In: Gestão Ambiental na Agropecuária. Vol.2. Embrapa. Brasília. 2014.

[8] SILVA, Sergio Peres Ramos; PALHA, Maria de Los Angeles Perez Fernandes. Inventário da Biomassa Produtora de Biogás de Pernambuco. Recife, 2016.

[9] DE OLIVEIRA, P. A. V. Manual de manejo e utilização dos dejetos de suínos. Embrapa Suínos e Aves-Documentos (INFOTECA-E), 1993.

[10] BITTON, Gabriel. Wastewater microbiology. John Wiley \& Sons, 2005. 